\title{
OPEN Effect of memantine, an anti-Alzheimer's drug, on rodent microglial cells in vitro
}

\author{
Toru Murakawa-Hirachi ${ }^{1,4}$, Yoshito Mizoguchi ${ }^{1,4} \bowtie$, Masahiro Ohgidani ${ }^{1,2,3}$, \\ Yoshinori Haraguchi ${ }^{1}$ \& Akira Monji ${ }^{1}$
}

The pathophysiology of Alzheimer's disease (AD) is related to neuroinflammatory responses mediated by microglia. Memantine, an antagonist of N-methyl-D-aspartate (NMDA) receptors used as an anti-Alzheimer's drug, protects from neuronal death accompanied by suppression of proliferation and activation of microglial cells in animal models of AD. However, it remains to be tested whether memantine can directly affect microglial cell function. In this study, we examined whether pretreatment with memantine affects intracellular $\mathrm{NO}$ and $\mathrm{Ca}^{2+}$ mobilization using DAF-2 and Fura-2 imaging, respectively, and tested the effects of memantine on phagocytic activity by human $\beta$-Amyloid (1-42) phagocytosis assay in rodent microglial cells. Pretreatment with memantine did not affect production of $\mathrm{NO}$ or intracellular $\mathrm{Ca}^{2+}$ elevation induced by TNF in rodent microglial cells. Pretreatment with memantine also did not affect the mRNA expression of pro-inflammatory (TNF, IL-1 $\beta$, IL-6 and CD45) or anti-inflammatory (IL-10, TGF- $\beta$ and arginase) phenotypes in rodent microglial cells. In addition, pretreatment with memantine did not affect the amount of human $\beta$-Amyloid (1-42) phagocytosed by rodent microglial cells. Moreover, we observed that pretreatment with memantine did not affect 11 major proteins, which mainly function in the phagocytosis and degradation of $\beta$-Amyloid (1-42), including TREM2, DAP12 and neprilysin in rodent microglial cells. To the best of our knowledge, this is the first report to suggest that memantine does not directly modulate intracellular $\mathrm{NO}$ and $\mathrm{Ca}^{2+}$ mobilization or phagocytic activity in rodent microglial cells. Considering the neuroinflammation hypothesis of $A D$, the results might be important to understand the effect of memantine in the brain.

Approximately 46.8 million people suffer from dementia, with an accompanying medical cost estimated at 818 billion dollars. Furthermore, the accumulation of $\beta$-Amyloid (1-42) is supposed to begin from 10 to 15 years before the onset of cognitive symptoms in patients suffering from Alzheimer's disease $(\mathrm{AD})^{1}$. In $\mathrm{AD}, \beta$-Amyloid (1-42) directly stimulates microglia to release both pro-inflammatory cytokines (such as TNFa) and nitric oxide $(\mathrm{NO})^{2}$ and promotes neuroinflammation resulting in neurodegeneration ${ }^{3}$. In addition, microglial senescence, typified by a decrease in phagocytic ability, is recently supposed to underlie mechanisms of both aging and $\mathrm{AD}^{4}$. Recently, many outstanding reports focus on triggering receptor expressed on myeloid cell 2 (TREM2) and/or DNAX-activating protein of $12 \mathrm{kDa}$ (DAP12), which are important for maintaining the phagocytic ability of microglia ${ }^{5,6}$.

For the treatment of patients suffering from $\mathrm{AD}$, we expect the appearance of disease-modifying drugs, which are fundamental treatments that suppress the progression of $\mathrm{AD}$ pathology $\mathrm{y}^{7,8}$. However, we need to continue to use currently available symptomatic drugs (i.e. donepezil, galantamine, rivastigmine and memantine) for the treatment of patients suffering from $\mathrm{AD}$, especially when $\mathrm{AD}$ is accompanied by behavioral and psychological symptoms of dementia (BPSD) ${ }^{9,10}$.

Memantine, an antagonist of N-methyl-D-aspartate receptors (NMDARs), has beneficial roles in the treatment of patients with moderate to severe $\mathrm{AD}$ because of its blockade of extra-synaptic NMDARs, which are activated by excess glutamate ${ }^{11}$. Microglia also express NMDARs, and application of high concentrations of NMDA release pro-inflammatory cytokines to induce death in cortical neurons ${ }^{12}$. In animal models of $\mathrm{AD}$, memantine has

\footnotetext{
${ }^{1}$ Department of Psychiatry, Faculty of Medicine, Saga University, 5-1-1 Nabeshima, Saga 849-8501, Japan. ${ }^{2}$ Department of Integrative Anatomy, Nagoya City University Graduate School of Medical Sciences, Nagoya 467-8601, Japan. ${ }^{3}$ Department of Neuropsychiatry, Graduate School of Medical Sciences, Kyushu University, 3-1-1 Maidashi, Higashi-ku, Fukuoka 812-8582, Japan. ${ }^{4}$ These authors contributed equally: Toru Murakawa-Hirachi and Yoshito Mizoguchi.『email: ymizo@cc.saga-u.ac.jp
} 


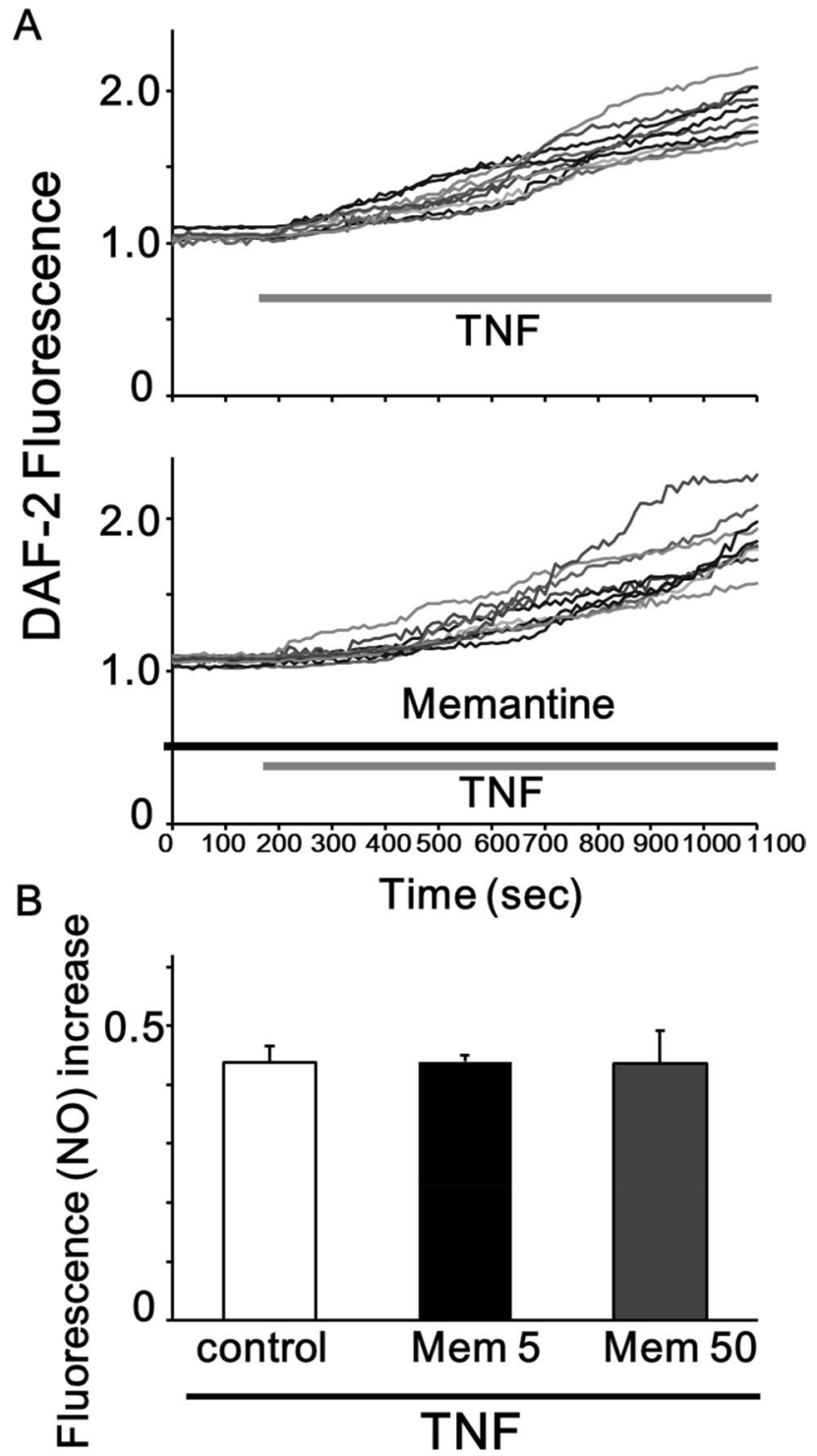

Figure 1. Pretreatment with memantine did not affect the production of NO induced by TNF in rat HAPI microglial cells. (A) Ten representative traces showing the treatment of $0.1 \mathrm{ng} / \mathrm{mL}$ TNF induced the increase in the DAF-2 fluorescence (upper) and $12 \mathrm{~h}$ pretreatment with $5 \mu \mathrm{M}$ memantine did not affect the TNFinduced increase in the DAF-2 fluorescence in rat HAPI microglial cells (lower). (B) Bar graphs showing that pretreatment with memantine did not the production of NO induced by TNF treatment. Pretreatment of memantine did not affect the amount of TNF-induced increase in the DAF-2 fluorescence at 15 min after a TNF-treatment in rat HAPI microglial cells $(0.437 \pm 0.024, \mathrm{n}=135$ cells in control; $0.439 \pm 0.023, \mathrm{n}=145$ cells in $5 \mu \mathrm{M}$ memantine; $\mathrm{p}=0.48$ ).

been reported to protect from neuronal death accompanied by suppression of proliferation and the activation of microglial cells ${ }^{13,14}$, As a direct effect of memantine on microglial cells, Tsai et al. reported that memantine suppresses the amplitude of inwardly rectifying $\mathrm{K}^{+}$currents, resulting in the depolarization of rodent microglial cells ${ }^{15}$. However, it remains to be tested whether pretreatment with memantine directly affects the intracellular $\mathrm{NO}$ and $\mathrm{Ca}^{2+}$ mobilization and/or phagocytic activity in rodent microglial cells. The protocol of experiments in this study was referred to in our previous report suggesting that donepezil, another anti-Alzheimer's drug, has a direct effect on rodent microglial function ${ }^{16}$.

\section{Results}

Pretreatment with memantine did not affect production of $\mathrm{NO}$ or intracellular $\mathrm{Ca}^{2+}$ elevation induced by TNF in rodent microglial cells (rat HAPI, mouse 6-3 and mouse primary microglial cells). We examined whether TNF induces intracellular NO mobilization in rat HAPI microglial cells using DAF-2 imaging. We observed that an application of TNF $(0.1 \mathrm{ng} / \mathrm{mL})$ induced a gradual increase in DAF-2 fluorescence which reflects endogenously produced NO in rat HAPI microglial cells ( $n=135$ cells; Fig. 1a upper) ${ }^{16,17}$. In addition, in the presence of L-N6-(1-iminoethyl)lysine (L-NIL; $50 \mu \mathrm{M})$, a membrane-permeant selective 

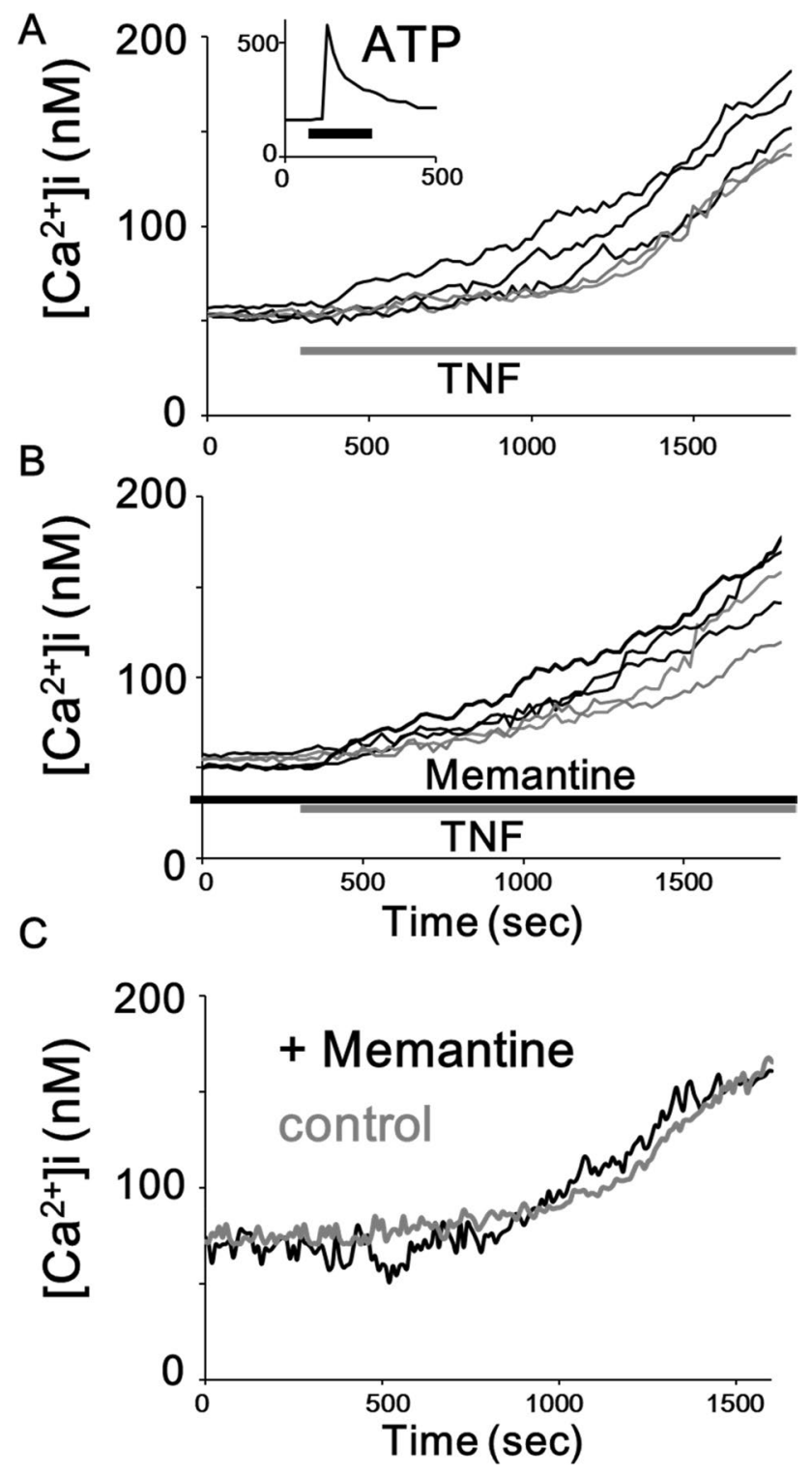

Figure 2. Pretreatment with memantine did not affect the elevation of $\left[\mathrm{Ca}^{2+}\right] \mathrm{i}$ induced by TNF in rodent microglial cells. (A) Five representative traces showing a treatment of $3 \mathrm{ng} / \mathrm{mL}$ TNF-induced sustained increase in $\left[\mathrm{Ca}^{2+}\right] \mathrm{i}$ in mouse primary microglial cells. (A, inset) The inset shows a $100 \mu \mathrm{M}$ ATP-induced transient increase in $\left[\mathrm{Ca}^{2+}\right] \mathrm{i}$ in mouse primary microglial cells. The average trace of $10\left[\mathrm{Ca}^{2+}\right] \mathrm{i}$ traces in response to ATP is shown. (B) Five representative traces showing pretreatment with memantine did not affect the elevation of $\left[\mathrm{Ca}^{2+}\right] \mathrm{i}$ induced by TNF in mouse primary microglial cells. (C) Average traces of $5\left[\mathrm{Ca}^{2+}\right] \mathrm{i}$ traces showing a treatment of $3 \mathrm{ng} / \mathrm{mL}$ TNF-induced sustained increase in $\left[\mathrm{Ca}^{2+}\right] \mathrm{i}$ in mouse $6-3$ microglial cells. Pretreatment with memantine did not affect the elevation of $\left[\mathrm{Ca}^{2+}\right]$ i induced by TNF in mouse 6-3 microglial cells.

inhibitor of inducible nitric oxide synthase (iNOS) ${ }^{20}$, TNF did not elevate the DAF-2 fluorescence in rat HAPI microglial cells $(n=60$ cells; data not shown). We also observed that the increase in intracellular DAF- 2 fluorescence was sustained for more than 50 min even after the TNF washout. Because the reaction between NO and DAF-2 is shown to be irreversible, the DAF-2 fluorescence level has been reported to reflect the total amount of NO produced in the cells ${ }^{18,19}$.

We next measured the effect of pretreatment with memantine $(5 \mu \mathrm{M} ; 12 \mathrm{~h})$ on the TNF-induced production of intracellular NO in rat HAPI microglial cells. In rat HAPI microglial cells, which were pretreated with memantine, TNF $(0.1 \mathrm{ng} / \mathrm{mL})$ induced a gradual increase in the DAF-2 fluorescence (Fig. 1a lower). On the other hand, we observed pretreatment of memantine did not affect the amount of TNF-induced increase in the DAF-2 fluorescence at $15 \mathrm{~min}$ after a TNF-treatment in rat HAPI microglial cells $(0.437 \pm 0.024, \mathrm{n}=135$ cells in control; $0.439 \pm 0.023, \mathrm{n}=145$ cells in $5 \mu \mathrm{M}$ memantine; $\mathrm{p}=0.48$; Fig. $1 \mathrm{~b})$. We also observed that pretreatment with $50 \mu \mathrm{M}$ memantine did not affect the TNF-induced production of NO $(0.436 \pm 0.046, n=47$ in memantine; $\mathrm{p}=0.49$; Fig. 1b). These suggest that memantine pretreatment did not affect the TNF-induced production of NO. 
Next, we observed that TNF $(3 \mathrm{ng} / \mathrm{mL})$ induces a sustained elevation of $\left[\mathrm{Ca}^{2+}\right]$ i in mouse primary microglial cells (Fig. 2a) as previously ${ }^{16,17}$. On contrary, an application of ATP $(100 \mu \mathrm{M})$ rapidly elevates $\left[\mathrm{Ca}^{2+}\right] \mathrm{i}$ in mouse primary microglial cells (Fig. 2a, inset). We next examined whether pretreatment with memantine has any effects on the sustained elevation of $\left[\mathrm{Ca}^{2+}\right]$ i. induced by TNF. We pretreated mouse primary microglial cells with memantine $(5 \mu \mathrm{M} ; 12 \mathrm{~h})$. We observed that memantine could not affect the elevation of $\left[\mathrm{Ca}^{2+}\right] \mathrm{i}$ induced by TNF in mouse primary microglial cells $(92.8 \pm 7.7 \mathrm{nM}, \mathrm{n}=137$ cells in control; $88.3 \pm 8.9 \mathrm{nM}, \mathrm{n}=136$ cells in memantine; $\mathrm{p}=0.35$; Fig. 2b). We also observed that pretreatment with memantine did not affect the TNF-induced elevation of $\left[\mathrm{Ca}^{2+}\right] \mathrm{i}$ in mouse 6-3 microglial cells $(22.1 \pm 18.9 \mathrm{nM}, \mathrm{n}=34$ cells in control; $20.4 \pm 14.2 \mathrm{nM}, \mathrm{n}=27$ cells in memantine; $\mathrm{p}=0.47$; Fig. $2 \mathrm{c}$ ). These results suggest that memantine did not have effects on the TNF-induced elevation of $\left[\mathrm{Ca}^{2+}\right] \mathrm{i}$ in rodent microglial cells.

Pretreatment with memantine did not affect the mRNA expression in pro- or anti-inflammatory phenotypes in rodent microglial cells (mouse primary microglial cells). In mouse primary microglial cells, we observed that memantine $(5 \mu \mathrm{M} ; 12 \mathrm{~h})$ did not have significant effects on the expressed level of mRNA of TNF, IL-1 $\beta$, IL- 6 and CD45 which represent pro-inflammatory markers using qRT-PCR. Memantine did not have significant effects on the expressed level of mRNA of IL-10, TGF- $\beta$ and arginase which represent anti-inflammatory markers (Fig. 3).

Pretreatment with memantine did not affect phagocytic activity of rodent microglial cells (mouse primary microglial cells). We next investigated whether pretreatment of memantine affects the phagocytic activity of mouse primary microglial cells. We observed that pretreatment of $5 \mu \mathrm{M}$ memantine for $12 \mathrm{~h}$ did not affect the amount of $\beta$-Amyloid (1-42) phagocytosed by mouse primary microglial cells $(\mathrm{n}=65$ cells in control; $n=61$ cells in memantine from 4 independent experiments each; Fig. 4). These suggest that pretreatment with memantine did not affect the phagocytic activity of rodent microglial cells.

Effects of pretreatment with memantine on the expression of phagocytosis-related proteins in rodent microglial cells (mouse 6-3 microglial cells). We next examined whether pretreatment of memantine affects the related proteins, which mainly function in the phagocytosis of mouse 6-3 microglial cells using flow cytometry. We observed that pretreatment of $5 \mu \mathrm{M}$ memantine for $12 \mathrm{~h}$ did not affect the amount of both TREM2 and DAP12, both of which are important for the phagocytic activity of microglia, expressed on mouse 6-3 microglial cells $(n=9$ for TREM2 and $n=9$ for DAP12 from 9 independent experiments each; Fig. 5a,b). In addition, we observed that pretreatment of $5 \mu \mathrm{M}$ memantine for $12 \mathrm{~h}$ did not affect the amount of neprilysin, which is a $\beta$-Amyloid (1-42)-degrading enzyme important for the clearance of $\beta$-Amyloid (1-42) by microglia, expressed on mouse 6-3 microglial cells $(n=9$ from 9 independent experiments; Fig. 5c). Moreover, we observed that pretreatment with memantine did not affect other eight proteins which mainly function in the phagocytosis, degradation of $\beta$-Amyloid (1-42) and/or intercellular signaling in mouse 6-3 microglial cells (Table 1). Specifically, pretreatment with memantine did not affect the amount of any of the following proteins including CX3CR1, CR3(CD11b/c), CD68, Dectin-1/Clec7a, Prostaglandin E synthase (PTGEs), Suppressor of cytokine signaling 3 (Socs3), ADAM10 and ADAM17. However, we observed that pretreatment with memantine significantly increased the amount of expression of A disintegrin and metalloproteinase with thrombospondin motifs 4 (ADAMTS4) and ATP binding cassette subfamily a member 7 (ABCA7) in mouse 6-3 microglial cells (Table 1).

Effects of pretreatment with MK801, another antagonist of NMDARs, on production of NO, intracellular $\mathrm{Ca}^{2+}$ elevation and phagocytic activity in rodent microglial cells (mouse 6-3 and mouse primary microglial cells). Mouse primary microglial cells are reported to express NMDARs including both NMDAR1 and NMDAR2A subunits ${ }^{12}$. We used flow cytometry to examine the expression of NMDARs to confirm the presence and maturation of NMDARs in mouse 6-3 microglial cells. We observed that both NMDAR1 and NMDAR2A were expressed in mouse 6-3 microglial cells $(\mathrm{n}=4$ obtained from 4 independent experiments each; Fig. S1a,b).

We next measured the effect of pretreatment with MK801, another antagonist of NMDARs, on the TNFinduced production of intracellular NO in mouse 6-3 microglial cells. We observed pretreatment of MK801 $(10 \mu \mathrm{M} ; 12 \mathrm{~h})$ did not affect the amount of TNF-induced increase in the DAF-2 fluorescence at $15 \mathrm{~min}$ after a TNF-treatment in mouse $6-3$ microglial cells $(0.428 \pm 0.033, \mathrm{n}=126$ cells in control; $0.465 \pm 0.028, \mathrm{n}=178$ cells in MK801; $\mathrm{p}=0.12$; Fig. S2a-c). In addition, we also observed that MK801 could not affect the elevation of $\left[\mathrm{Ca}^{2+}\right]$ $\mathrm{i}$ induced by TNF in both mouse primary microglial cells $(92.8 \pm 7.7 \mathrm{nM}, \mathrm{n}=137$ cells in control; $94.1 \pm 7.9 \mathrm{nM}$, $\mathrm{n}=132$ cells in MK801; $\mathrm{p}=0.41$; Fig. S2d,e) and mouse 6-3 microglial cells (not shown). Lastly, we observed that pretreatment with $10 \mu \mathrm{M}$ MK-801 did not affect the amount of $\beta$-Amyloid (1-42) phagocytosed by mouse primary microglial cells ( $\mathrm{n}=165$ cells in control; $\mathrm{n}=198$ cells in MK801 from 5 independent experiments each; Fig. S2f).

\section{Discussion}

In the present study, we observed that pretreatment with memantine did not affect either production of NO or intracellular $\mathrm{Ca}^{2+}$ elevation induced by TNF in rodent microglial cells. Pretreatment with memantine did not affect the mRNA expression of either pro-inflammatory (TNF, IL-1 $\beta$, IL- 6 and CD45) or anti-inflammatory (IL10 , TGF- $\beta$ and arginase) phenotypes in mouse primary microglial cells. In addition, pretreatment with memantine did not affect the amount of $\beta$-Amyloid (1-42) phagocytosed by mouse primary microglial cells. Moreover, we observed that pretreatment with memantine did not affect 11 major proteins, which mainly function in the 

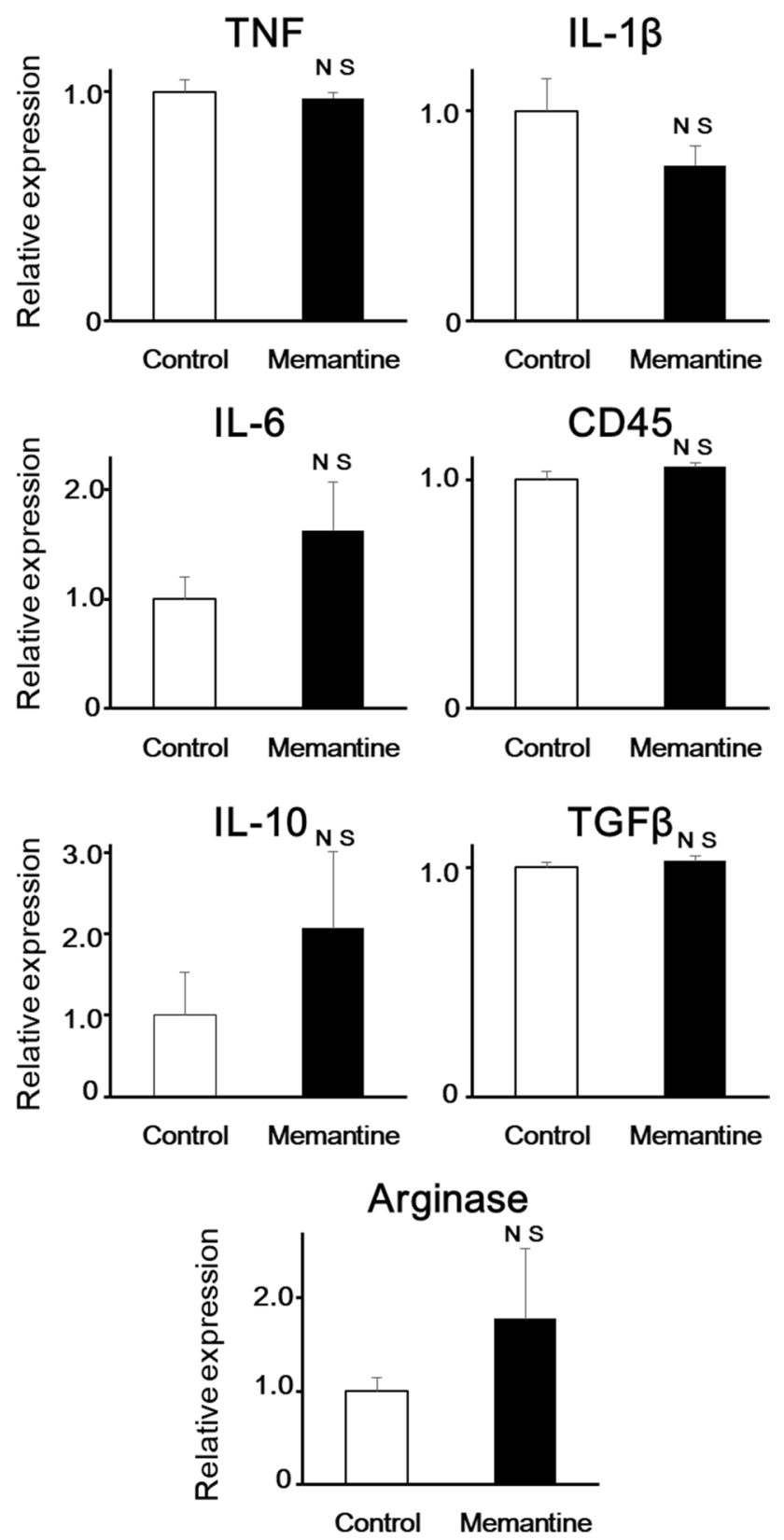

Figure 3. Pretreatment with memantine did not affect the mRNA expression of both pro- and antiinflammatory phenotypes in mouse primary microglial cells. Bar graphs showing the effects of pretreatment with memantine on mRNA expression of TNF, IL-1 $\beta$, IL-6, CD45, IL-10, TGF- $\beta$, and arginase in mouse primary microglial cells. NS not significant vs control.

phagocytosis, degradation of $\beta$-Amyloid (1-42) and/or intercellular signaling, including TREM2, DAP12 and neprilysin, in mouse 6-3 microglial cells. To the best of our knowledge, this is the first report to test the direct effects of pretreatment with memantine on rodent microglial functions.

Excessive and long-term activation of NMDARs induces excitotoxicity, ultimately leading to neurodegeneration ${ }^{21}$. Memantine is shown to prevent excess $\mathrm{Ca}^{2+}$ entry through NMDARs induced by treatment with Amyloid- $\beta$ oligomers (A $\beta \mathrm{Os}$ ) in cultured neurons prepared from mice ${ }^{22}$. Microglia also expresses NMDARs and applications of a high concentration of NMDA are shown to release pro-inflammatory cytokines and to induce the death of cortical neurons ${ }^{12}$. In animal models of $\mathrm{AD}$, memantine has been reported to protect neuronal death accompanied by suppressing both the proliferation and activation of microglial cells ${ }^{13,14}$. However, these reports did not show memantine directly affects microglial functions in their examinations. In the present study, we suggest that memantine could not directly modulate the microglial functions including intracellular $\mathrm{NO}$ and $\mathrm{Ca}^{2+}$ mobilization in rodent microglial cells. In addition, we also examined whether pretreatment of memantine directly affects the related proteins, which mainly function in the phagocytosis of rodent microglial cells using flow cytometry. We observed that pretreatment of memantine did not affect the amount of both 


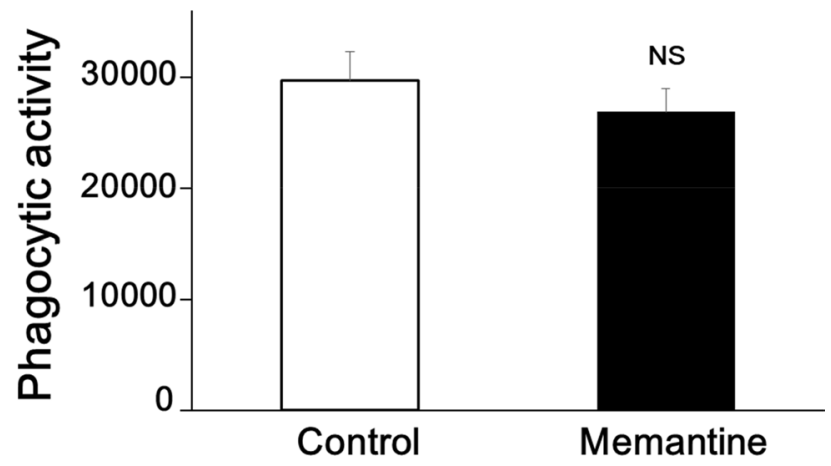

Figure 4. Pretreatment with memantine did not affect phagocytic activity of mouse primary microglial cells. Bar graph showing pretreatment of $5 \mu \mathrm{M}$ memantine for $12 \mathrm{~h}$ did not affect the amount of $\beta$-Amyloid (1-42) phagocytosed by mouse primary microglial cells $(n=65$ cells in control; $n=61$ cells in memantine from 4 independent experiments each).

A

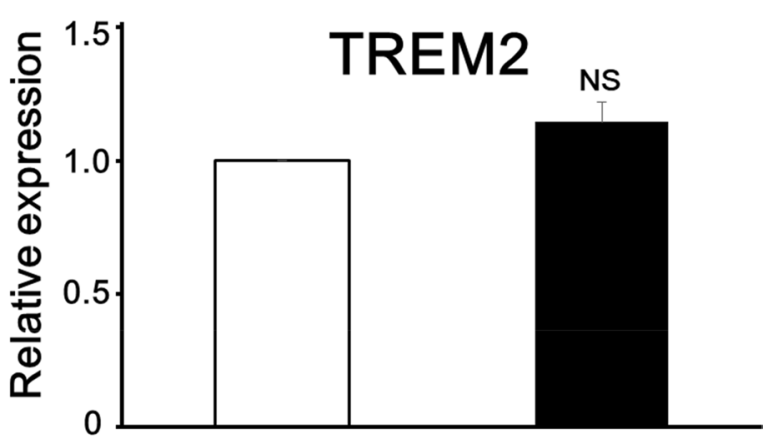

B

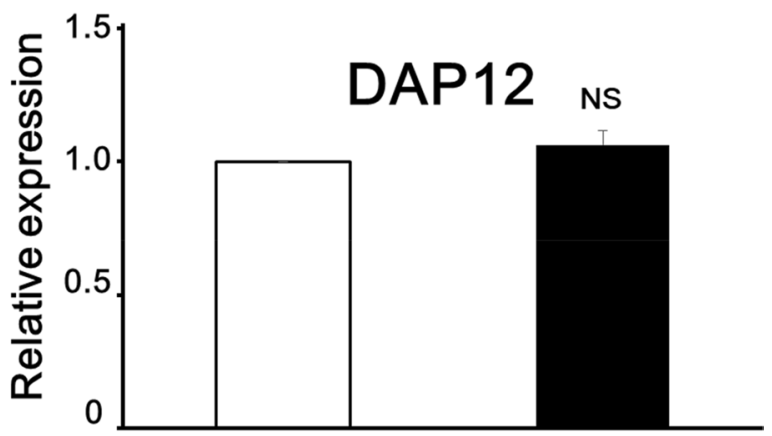

C

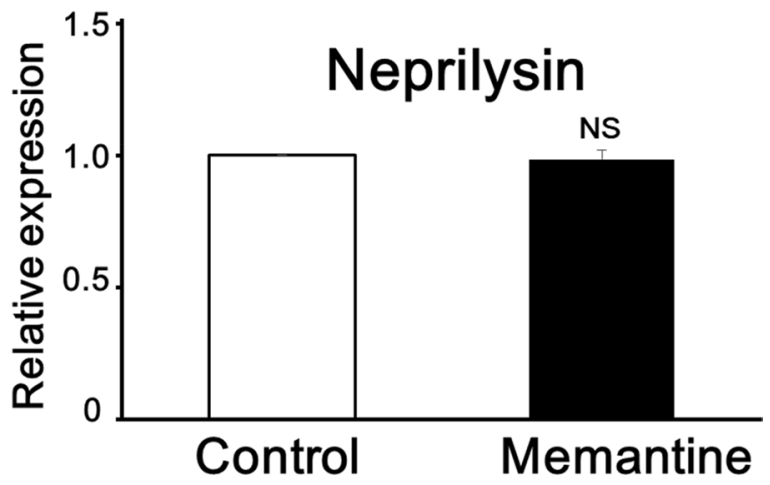

Figure 5. Effects of pretreatment with memantine on the expression of phagocytosis-related proteins in mouse 6-3 microglial cells. Bar graphs showing that pretreatment of $5 \mu \mathrm{M}$ memantine for $12 \mathrm{~h}$ did not affect the amount of TREM2 (A), DAP12 (B) and neprilysin (C) expressed on mouse 6-3 microglial cells ( $\mathrm{n}=9$ for TREM2, DAP12 and neprilysin from 9 independent experiments each). 


\begin{tabular}{|c|c|c|}
\hline Effects of memantine & Function in microglial cells & References \\
\hline \multicolumn{3}{|l|}{ Potentiation } \\
\hline ABCA7 & $\begin{array}{l}\text { ABCA7 is important for microglial phagocytic activity. Deletion of ABCA7 in AD mouse exacerbates cerebral } A \beta \text { plaque } \\
\text { load }\end{array}$ & 28,29 \\
\hline ADAMTS4 & $\begin{array}{l}\text { ADAMTS4 increases the number of microglia expressing arginase-1, a marker of anti-inflammatory functions in the } \\
\text { ischemic brain }\end{array}$ & 27 \\
\hline \multicolumn{3}{|c|}{ S } \\
\hline TREM2 & $\begin{array}{l}\text { TREM2 promotes proliferation and enhances phagocytosis of microglia, while recent reports suggesting a complex } \\
\text { action of TREM2 on inflammatory processes because of both pro- or anti-inflammatory properties }\end{array}$ & 6,23 \\
\hline DAP12 & $\begin{array}{l}\text { Adaptor protein gets phosphorylated, recruits SYK, and activates intracellular pathways such as PI3K and/or MAPK } \\
\text { when binding to TREM2 ligands }\end{array}$ & 24,25 \\
\hline Neprilysin & Microglia can phagocytose $A \beta$ and also clear $A \beta$ by degradation via $A \beta$ degrading proteases, neprilysin & 26 \\
\hline CX3CR1 & $\begin{array}{l}\text { Microglial activity is restrained by fractalkine (CX3CL1) derived from neurons and cognate receptors on microglia, } \\
\text { CX3CR1, in normal brain }\end{array}$ & 42 \\
\hline $\mathrm{CR} 3(\mathrm{CD} 11 \mathrm{~b} / \mathrm{c})$ & CR3 is surface complement receptor involved in clearance of weak synapses mediated by microglial phagocytosis & 43 \\
\hline CD68 & $\begin{array}{l}\text { CD68, a lysosomal/endosomal associated membrane glycoprotein, is a marker for either activated and/or senescent } \\
\text { microglia }\end{array}$ & 44 \\
\hline Dectin-1/Clec7a & Dectin-1/Clec7a is a pattern recognition receptor involved in the microglial phagocytosis of beta-glucan particles & 45 \\
\hline PTGEs (Prostaglandin E synthase) & PTGEs produces eicosanoid prostaglandin E2 (PGE2) which plays important roles in neuroinflammation and AD brain & 46 \\
\hline Socs3 (suppressor of cytokine signaling 3) & $\begin{array}{l}\text { SOCS3 suppresses JAK/STAT3 pathway resulting in cytokine signaling and has anti-inflammatory roles in the brain of } \\
\text { AD mouse }\end{array}$ & 47,48 \\
\hline ADAM10 & $\begin{array}{l}\text { ADAM10, one of four loci recently identified as risk genes of AD, is expressed in microglia and it cleaves CX3CL1 into a } \\
\text { secreted form to remodel synapses }\end{array}$ & 49,50 \\
\hline ADAM17 & $\begin{array}{l}\text { ADAM17 inhibits clearance of apoptotic cells by microglia while it potentiates cleavage of amyloid precursor protein } \\
\text { resulting in reduction of } \mathrm{A} \beta \text { generation }\end{array}$ & 51,52 \\
\hline \multicolumn{3}{|c|}{ 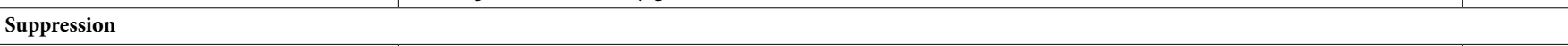 } \\
\hline None & & \\
\hline
\end{tabular}

Table 1. Effects of pretreatment with memantine on the expression of phagocytosis-related proteins in mouse 6-3 microglial cells measured using flow cytometry.

TREM2 and DAP12, both of which are important for the phagocytic activity of microglia ${ }^{6,23-25}$. We also observed that pretreatment of memantine did not affect the amount of neprilysin, which is a $\beta$-Amyloid (1-42)-degrading enzyme important for the clearance of $\beta$-Amyloid (1-42) by microglia ${ }^{26}$. Moreover, we observed that pretreatment with memantine did not affect other eight proteins which mainly function in the phagocytosis, degradation of $\beta$-Amyloid (1-42) and/or intercellular signaling in rodent microglial cells (Table 1). Specifically, pretreatment with memantine did not affect the amount of any of the following proteins including CX3CR1, CR3(CD11b/c), CD68, Dectin-1/Clec7a, Prostaglandin E synthase (PTGEs), Suppressor of cytokine signaling 3 (Socs3), ADAM10 and ADAM17. However, we observed that pretreatment with memantine significantly increased the amount of expression of A disintegrin and metalloproteinase with thrombospondin motifs 4 (ADAMTS4) and ATP binding cassette subfamily a member 7 (ABCA7) in mouse 6-3 microglial cells (Table 1). ADAMTS4 is one of metalloproteases to degrade chondroitin sulfate proteoglycans leading to destruction of cartilage during arthritis or spinal cord injury. In addition, ADAMTS4 is shown to increase the number of microglia expressing arginase 1 , a marker of anti-inflammatory functions in the brain of mouse model of ischemic stroke ${ }^{27}$. Loss-of-function variants of ABCA7 increases the risk of susceptibility to Alzheimer's disease (AD) in Icelanders ${ }^{28}$. ABCA7 is important for microglial phagocytic activity and deletion of ABCA7 exacerbate the load of A $\beta$ plaque in the cerebral cortex of mouse model of $\mathrm{AD}^{29}$. Thus, memantine could directly affect some proteins to augment the function of microglial cells leading to protect neuronal death in animal models of AD. Although we observed that pretreatment with memantine did not affect 11 of 13 major proteins, we cannot conclude that memantine has no direct effects on phagocytosis and degradation of $\beta$-Amyloid (1-42) mainly mediated by microglial cells. In addition, we need to be aware that mRNA and protein levels could not match in the same experiments.

Mouse primary microglial cells are reported to express NMDARs including both NMDAR1 and NMDAR2A subunits $^{12}$. We also observed that both NMDAR1 and NMDAR2A were expressed in mouse 6-3 microglial cells we used. In addition, we observed pretreatment of $10 \mu \mathrm{M}$ MK801, another antagonist of NMDARs, did not affect both production of $\mathrm{NO}$ and intracellular $\mathrm{Ca}^{2+}$ mobilization induced by TNF in rodent microglial cells. We used $10 \mu \mathrm{M}$ MK801 because MK801 with the same concentration suppressed the NMDA-induced intracellular calcium responses in mouse primary cells ${ }^{12}$. In the present study, we also observed that pretreatment with MK801did not affect phagocytic activity of mouse primary microglial cells. It requires further research to elucidate whether microglial cells express functional NMDARs. Previous reports show that microglial cells do not express functional NMDARs in the rodent brain ${ }^{30-32}$. We also observed that an application of glutamate did not elevate $\left[\mathrm{Ca}^{2+}\right] \mathrm{i}$ in any of rat HAPI microglial cells, mouse 6-3 microglial cells and mouse primary microglial cells (unpublished data). To the best of our knowledge, only two reports have clearly shown the presence of functional NMDARs in microglial cells ${ }^{12,33}$. Unfortunately, the two reports examined the effects of MK801, but not the effects of memantine, on microglial functions. In HEK-293 cells, Gilling et al. have previously reported that the antagonistic effects of memantine are strongly voltage-dependent ${ }^{34}$. Thus, it is possible that voltage-dependency could affect the results of our failure to observe the effects of both memantine and MK801 on microglial cellular 
functions. We have previously reported that pretreatment with donepezil, an acetylcholinesterase inhibitor, directly modulates the microglial functions, including intracellular $\mathrm{NO}$ and $\mathrm{Ca}^{2+}$ mobilization and phagocytic ability in rodent microglial cells, through the phosphatidylinositol-3 kinase (PI3K) pathway ${ }^{16}$. It is possible that both memantine and MK801 did not affect the PI3K pathway in rodent microglial cells we used. There are no reports of whether NMDARs activate the PI3K pathway in microglia.

Although we noticed one major limitation of our observation is the reliance on the in vitro work of microglia activation, our in vitro work is compatible with the in vivo studies which reports that memantine improves cognitive dysfunction through the indirect effects rather than direct modulatory effects on microglia ${ }^{13,14}$.

\section{Conclusions}

We herein observed that memantine could not directly modulate intracellular $\mathrm{NO}$ and $\mathrm{Ca}^{2+}$ mobilization and phagocytic activity in rodent microglial cells. These results could be important to understand the effect of memantine for the treatment of $\mathrm{AD}$.

\section{Methods}

Materials. The drugs used in the present study include memantine, 4,5-diaminofluorescein diacetate (DAF2DA), Fura2-AM, human recombinant TNFa, adenosine 5' triphosphate (ATP) (all from Sigma-Aldrich, St. Louis, MO), (+)-MK801 Maleate (R\&D Systems, Inc. MN) and $\beta$-Amyloid (1-42), 5-FAM-labeled (AnaSpec Inc., CA). Human recombinant TNFa was diluted with the standard external solution to obtain a final concentration. Memantine was diluted with the standard external solution to obtain a final concentration $(5 \mu \mathrm{M})$. This memantine concentration is sufficient to antagonize the NMDA receptor-mediated currents in cultured hippocampal neurons ${ }^{35}$ or to prevent neurotoxicity in rat cortical neurons ${ }^{36}$. In addition, we used donepezil at the same concentration in our previous report ${ }^{16}$. Drugs that were insoluble in water were first dissolved in dimethylsulfoxide (DMSO; Wako Pure Chemical Industries, Osaka, Japan), then diluted in the standard external solution. The final concentration of DMSO was always less than $0.1 \%$.

Rodent microglial cells. Primary microglial cells were prepared from the whole brain of 8-week-old male C57BL/6 J mice (CLEA Japan, Inc., Tokyo, Japan) using magnetic-activated cell sorting as we have reported ${ }^{16,17}$. Mouse brain tissues were dissociated enzymatically with a Neural Tissue Dissociation Kit (Miltenyi Biotec, Auburn, CA) according to the manufacturer's protocol. Briefly, mouse brain tissues were minced with a scalpel, and pre-warmed enzyme mix solution was added to the tissue pieces. After enzymatic dissociation, dissociated tissues were filtered with a $70-\mu \mathrm{m}$ pore-size cell strainer, and centrifuged. Pellets were re-suspended in MACS buffer (Miltenyi Biotec, Auburn, CA) supplemented with magnetic myelin removal beads (Miltenyi Biotec, Auburn, CA) and incubated for $15 \mathrm{~min}$. Myelin was removed by magnetic separation using LS columns (Miltenyi Biotec, Auburn, CA). To separate primary microglia, cells were magnetically labeled with CD11b MicroBeads (Miltenyi Biotec). CD11b + cells were isolated by LS columns (Miltenyi Biotec), and isolated cells were cultured with DMEM containing $10 \%$ FBS, $1 \%$ antibiotics, and $1 \mathrm{ng} / \mathrm{mL}$ GM-CSF. The purity of isolated microglia was assessed by immunocytochemical staining for the microglial marker, Iba-1, and $>99 \%$ of cells stained positively.

The 6-3 microglial cells were established from neonatal C57BL/6J (H-2b) mice as described previously ${ }^{22,37}$. The 6-3 cells were cultured in Eagle's MEM supplemented with $0.3 \% \mathrm{NaHCO}_{3}, 2 \mathrm{mM}$ glutamine, $0.2 \%$ glucose, $10 \mathrm{~g} / \mathrm{mL}$ insulin and $10 \% \mathrm{FBS}$. Cells were maintained at $37^{\circ} \mathrm{C}$ in a $10 \% \mathrm{CO} 2,90 \%$ air atmosphere. GM-CSF was supplemented into the culture medium at a final concentration of $1 \mathrm{ng} / \mathrm{mL}$, to maintain proliferation of the 6-3 cells. Culture media was renewed twice per week.

The rat microglial cell line, highly aggressive proliferating immortalized (HAPI) cells, was kindly donated by Drs. N. P. Morales and F. Hyodo of Kyushu University (Japan). The cells were cultured in DMEM (low glucose; Invitrogen, Waltham, MA), 5\% FBS (Hyclone, Logan, UT), 4 mM glutamine (Invitrogen, Waltham, MA), 100,000 $\mathrm{U} / \mathrm{L}$ Penicillin G, $100 \mathrm{mg} / \mathrm{L}$ streptomycin (Mediatech, Tewksbury, MA), and maintained in $5 \% \mathrm{CO}_{2}$ at $37^{\circ} \mathrm{C}$ as previously reported ${ }^{16,17}$.

All experiments were performed in accordance with the guidelines for the care and use of experimental animals by the Japanese Association for Laboratory Animals Science (1987) and were approved by the Saga University Animal Care and Use Committee and carried out according to the Saga University Animal Experimentation Regulations. In addition, all methods were carried out in accordance with the Saga University Animal Experimentation Regulations. This study was carried out in compliance with the ARRIVE guidelines.

Intracellular NO imaging. The experiments were performed as described previously ${ }^{16,17}$. The microglial cells were loaded with $10 \mu \mathrm{M}$ DAF-2DA (4,5-diaminofluorescein diacetate; Sigma-Aldrich, St. Louis, MO), a cell-membrane-permeable dye that binds intracellular $\mathrm{NO}^{18}$, for 20 min before measurement. For DAF- 2 excitation, the cells were illuminated at a $490-\mathrm{nm}$ wavelength using a computerized system. The signal obtained at $490 \mathrm{~nm}$ was previously shown to be, among the excitation wavelengths, quantitatively the largest and most representative of change in intracellular $\mathrm{NO}^{38}$. The emitted light was collected at $510 \mathrm{~nm}$ using a cooled CCD camera. The intracellular DAF-2 fluorescence intensity (F) was recorded for each pixel within a cell boundary. The ratio (F/F0) of fluorescence intensity was estimated from the intensity of fluorescence recorded prior to stimulation (F0).

Intracellular $\mathrm{Ca}^{2+}$ imaging. Intracellular $\mathrm{Ca}^{2+}$ imaging using fura-2 $\mathrm{AM}$ was performed as reported previously ${ }^{16,17,37,39}$. In brief, the experiments were performed in the external standard solution (in mM: 150 $\mathrm{NaCl}, 5 \mathrm{KCl}, 2 \mathrm{CaCl}_{2}, 1 \mathrm{MgCl}_{2}, 10$ glucose and $10 \mathrm{HEPES}$, pH 7.4 with Tris-OH) at room temperature $\left(27^{\circ} \mathrm{C}\right)$. 


\begin{tabular}{|c|c|}
\hline Antigen protein & Antibody \\
\hline ADAMTS4 & Anti-ADAMTS4 polyclonal antibody, ALEXA FLUOR 555 conjugated bs-4191R-A555 BIS \\
\hline ABCA7 & Anti-ABCA7 polyclonal antibody, ALEXA FLUOR 647 conjugated bs-11180R-A647 BIS \\
\hline TREM2 & Anti-TREM2 polyclonal antibody, ALEXA FLUOR 647 conjugated bs-2723R-A647 BIS \\
\hline DAP12 & Anti-DAP12 polyclonal antibody, FITC conjugated bs-12630R-FITC BIS \\
\hline Neprilysin & $\begin{array}{l}\text { Anti-neprilysin/CD10 polyclonal antibody, ALEXA FLUOR } 647 \text { conjugated bs-0527R-A647 } \\
\text { BIS }\end{array}$ \\
\hline CX3CR1 & Anti-CX3CR1 polyclonal antibody, FITC conjugated bs-1728R-FITC BIS \\
\hline $\mathrm{CR} 3(\mathrm{CD} 11 \mathrm{~b} / \mathrm{c})$ & AntiCD11b/c polyclonal antibody, PE conjugated bs-1014R-PE BIS \\
\hline CD68 & Anti-CD68 polyclonal antibody, FITC conjugate bs-1432R-FITC BIS \\
\hline Clec7a/Dectin-1 & $\begin{array}{l}\text { Anti-Beta glucan receptor (Clec7a/Dectin-1) polyclonal antibody, ALEXA FLUOR } 555 \text { conju- } \\
\text { gated bs-2455R-A555 BIS }\end{array}$ \\
\hline PTGEs (Prostaglandin E synthase) & $\begin{array}{l}\text { Anti-PTGEs (prostaglandin E synthase) polyclonal antibody, FITC Conjugated, bs- } \\
\text { 1880R-FITC BIS }\end{array}$ \\
\hline Socs3 (suppressor of cytokine signaling 3) & Anti-Socs3 polyclonal antibody, FITC conjugated A61096-100 EPG \\
\hline ADAM10 & Anti-ADAM10 polyclonal antibody, ALEXA FLUOR 647 conjugated bs-3574R-A647 BIS \\
\hline ADAM17 & Anti-ADAM17 polyclonal antibody, PE conjugated bs-4236R-PE BIS \\
\hline NMDAR1 & Anti-NMDAR1 (Ser897) polyclonal antibody, FITC conjugated bs-3903R-FITC BIS \\
\hline NMDAR2 & Anti-NMDAR2A polyclonal antibody, ALEXA FLUOR 647 conjugated bs-3507R-A647 BIS \\
\hline
\end{tabular}

Table 2. Antibodies used for flow cytometry.

For fura-2 excitation, the cells were illuminated at two alternating wavelengths, 340 and $380 \mathrm{~nm}$, using a computerized system for a rapid dual wavelength Xenon arc. The emitted light was recorded at $510 \mathrm{~nm}$ using a cooled CCD camera (Hamamatsu Photonics, Japan). The intracellular $\mathrm{Ca}^{2+}$ concentration $\left[\mathrm{Ca}^{2+}\right]$ i was calculated from the ratio (R) of fluorescence recorded at 340 and $380 \mathrm{~nm}$ excitation wavelengths for each pixel within a microglial cell boundary. Calibrations (conversion of R340/380 values into calcium concentrations) were performed as described previously ${ }^{16,17,37,39}$, using a Fura-2 calcium imaging calibration kit (Molecular Probes, Eugene, OR). Basal $\left[\mathrm{Ca}^{2+}\right] \mathrm{i}$ was determined from the initial 12 images of each cell recording. A $\left[\mathrm{Ca}^{2+}\right]$ i signal was defined as an increase in R 340/380 with clear time correlation to the application of TNF. An increase of [Ca $\left.{ }^{2+}\right] \mathrm{i}$ in response to TNF was calculated as the difference between basal $\left[\mathrm{Ca}^{2+}\right] \mathrm{i}$ and values obtained at 15 min after treatment with TNF. We tested the effect of $100 \mu \mathrm{M}$ ATP on rodent microglial cells at the end of all experiments and used cells that showed transient intracellular $\mathrm{Ca}^{2+}$ elevation for analysis. All data presented were obtained from at least five dishes and three different cell preparations.

Quantitative real time-polymerase chain reaction (qRT-PCR). qRT-PCR was performed using a LightCycler 480 system (Roche Diagnostics, Mannheim, Germany) as previously reported ${ }^{16}$. The mouse primary microglial cells were pre-treated with memantine $(5 \mu \mathrm{M})$ for $12 \mathrm{~h}$. Cells were washed and the total RNA was extracted using a High Pure RNA Isolation kit (Roche Diagnostics) according to the manufacturer's protocol, and was subjected to cDNA synthesis using a Transcriptor First Strand cDNA Synthesis kit (Roche Diagnostics). qRT-PCR was performed with primers (TNF: 5'-CTGTAGCCCACGTCGTAGC-3', 3'-TTGAGATCCATG CCGTTG-5'; CD45: 5'-TCAGAAAATGCAACAGTGACAA-3', 3'-CCAACTGACATCTTTCAGGTATGA-5'; IL-1 $\beta$ : 5'-AGTTGACGGACCCCAAAAG-3', 3'-AGCTGGATGCTCTCATCAGG-5'; IL-6: 5'-GCTACCAAA CTGGATATAATCAGGA-3', 3'-CCAGGTAGCTATGGTACTCCAGAA-5'; IL-10: 5'-CAGAGCCACATGCTC CTAGA-3', $3^{\prime}$-TGTCCAGCTGGTCCTTTGTT-5'; TGF- $\beta$ : $5^{\prime}$-TGGAGCAACATGTGGAACTC-3', $3^{\prime}$-GTC AGCAGCCGGTTACCA-5'; Arginase: 5'-GAATCTGCATGGGCAACC-3', 3'-GAATCCTGGTACATCTGG GAAC- $5^{\prime}$ ). Actin- $\beta$ of Universal Probe Library (Roche Diagnostics) was used as a house-keeping control gene. All of these primers were used in our previous report ${ }^{16}$. The value of mRNA expression for each sample was automatically calculated as the Ratio by a LightCycler 480 system (Roche Diagnostics, Mannheim, Germany). Ratio $=2^{-\Delta \mathrm{Cp}}, \Delta \mathrm{Cp}=\mathrm{Cp}($ target $)-\mathrm{Cp}($ reference $)$.

Phagocytosis assay. Phagocytosis was examined via FSX100 Bio Imaging Navigator (Olympus Waltham, MA) using a Human $\beta$-Amyloid (1-42), 5-FAM-labeled according to the manufacturer's protocol. Primary microglial cells cultured in glass-based dishes were used. Human $\beta$-Amyloid (1-42), 5-FAM-labeled was reconstituted and diluted with $1 \mathrm{X}$ PBS and to a concentration of $3 \mu \mathrm{g} / \mathrm{mL}$ according to both the manufacturer's protocol and previous reports ${ }^{40,41}$. We incubated the cells in standard culture conditions for $3 \mathrm{~h}$. After aspirating the culture medium, the cells were fixed with $4 \%$ paraformaldehyde. Then, after discarding paraformaldehyde, we washed fixed cells with $1 \mathrm{~mL}$ phosphate buffered salts (PBS) twice and measured the fluorescence intensity of FAM along the long axis of the cytoplasm using an Imaging Navigator.

Flow cytometry. Flow cytometry was performed using a FACSVerse Flow Cytometer (BD Biosciences, San Jose, CA), as previously reported ${ }^{16}$. Flow cytometry data were analyzed using FlowJo v10.6.1 (BD Life Sciences Informatics, Ashland, OR). The mouse 6-3 microglial cells were harvested by nonenzymatic cell dissociation solution (Sigma) and a cell lifter (Corning). The cells were fixed with $4 \%$ paraformaldehyde and permeabi- 
lized with 0.1\% Triton X-100. After blocking of Fc receptors by FcR Blocking Reagent, mouse (Miltenyi Biotec, Auburn, CA), the cells were stained with each antibody and the fluorescence intensity of the cells was measured from 9 to 12 dishes (10,000 cells/dish) in each antibody condition. All antibodies used for flow cytometry are listed in Table 2.

Statistics. All statistical analyses were performed with Statistical Package for the Social Sciences (SPSS) software (version 18.0; SPSS Inc., Chicago, IL). All quantified data represent a mean \pm SEM. Statistical significance was determined by ANOVA and Tukey's post hoc test when more than two groups were compared, and Student's $\mathrm{t}$ test when one group was compared with the control group. $\mathrm{p}<0.05$ was considered significant.

Received: 2 June 2020; Accepted: 24 February 2021

Published online: 17 March 2021

\section{References}

1. McDade, E. \& Bateman, R. J. Stop Alzheimer's before it starts. Nature 547, 153-155 (2017).

2. Glass, C. et al. Mechanisms underlying inflammation in neurodegeneration. Cell 140, 918-934 (2010).

3. Ransohoff, R. M. How neuroinflammation contributes to neurodegeneration. Science 353, 777-783 (2016).

4. Streit, W. J., Xue, Q. S., Tischer, J. \& Bechmann, I. Microglial pathology. Acta Neuropathol. Commun. 2, 142 (2014).

5. Griciuc, A. et al. TREM2 acts downstream of CD33 in modulating microglial pathology in Alzheimer's disease. Neuron 103, 820-835 (2019).

6. Parhizkar, S. et al. Loss of TREM2 function increases amyloid seeding but reduces plaque-associated ApoE. Nat. Neurosci. 22, 191-204 (2019).

7. Kaiser, J. The Alzheimer's gamble. Science 361, 838-841 (2018).

8. Elmaleh, D. R. et al. Developing effective Alzheimer's disease therapies: Clinical experience and future directions. J. Alzheimers Dis. 71, 715-732 (2019).

9. Kales, H. C., Gitlin, L. N. \& Lyketsos, C. G. Assessment and management of behavioral and psychological symptoms of dementia. BMJ 350, h369 (2015)

10. Arvanitakis, Z., Shah, R. C. \& Bennett, D. A. Diagnosis and management of dementia: Review. JAMA 322, 1589-1599 (2019).

11. Reisberg, B. et al. Memantine in moderate-to-severe Alzheimer's disease. N. Engl. J. Med. 348, 1333-1341 (2003).

12. Kaindl, A. M. et al. Activation of microglial N-methyl-D-aspartate receptors triggers inflammation and neuronal cell death in the developing and mature brain. Ann. Neurol. 72, 536-549 (2012).

13. Rosi, S. et al. LPS-induced neuroinflammation, restores behaviorally-induced gene expression and spatial learning in the rat. Neuroscience 142, 1303-1315 (2006).

14. Wu, H. M. et al. Novel neuroprotective mechanisms of memantine: increase in neurotrophic factor release from astroglia and anti-inflammation by preventing microglial activation. Neuropsychopharmacology 34, 2344-2357 (2009).

15. Tsai, K. L., Chang, H. F. \& Wu, S. N. The inhibition of inwardly rectifying K+ channels by memantine in macrophages and microglial cells. Cell. Physiol. Biochem. 31, 938-951 (2013).

16. Haraguchi, Y. et al. Donepezil suppresses intracellular Ca2+ mobilization through the PI3K pathway in rodent microglia. J. Neuroinflammation 14, 258 (2017).

17. Mizoguchi, Y. et al. Brain-derived neurotrophic factor (BDNF) induces sustained intracellular $\mathrm{Ca}^{2+}$ elevation through the upregulation of surface transient receptor potential 3 (TRPC3) channels in rodent microglia. J. Biol. Chem. 289, 18549-18555 (2014).

18. Kojima, H. et al. Detection and imaging of nitric oxide with novel fluorescent indicators: Diaminofluoresceins. Anal. Chem. 70, 2446-2453 (1998).

19. Kalinchuk, A. V., McCarley, R. W., Porkka-Heiskanen, T. \& Basheer, R. Sleep deprivation triggers inducible nitric oxide-dependent nitric oxide production in wake-active basal forebrain neurons. J. Neurosci. 30, 13254-13264 (2010).

20. Moore, W. M. et al. L-N6-(1-iminoethyl)lysine: A selective inhibitor of inducible nitric oxide synthase. J. Med. Chem. 37, 3886-3888 (1994).

21. Hardy, J. \& Cowburn, R. Glutamate neurotoxicity and Alzheimer's disease. Trends Neurosci. 10, 406 (1987).

22. Kodis, E. J. et al. N-methyl-D-aspartate receptor-mediated calcium influx connects amyloid- $\beta$ oligomers to ectopic neuronal cell cycle reentry in Alzheimer's disease. Alzheimers Dement. 14, 1302-1312 (2018).

23. Gratuze, M., Leyns, C. E. G. \& Holtzman, D. M. New insights into the role of TREM2 in Alzheimer's disease. Mol. Neurodegener. 13, 66 (2018).

24. Lanier, L. L. et al. Immunoreceptor DAP12 bearing a tyrosine-based activation motif is involved in activating NK cells. Nature 391, 703-707 (1998).

25. Takahashi, K., Rochford, C. D. \& Neumann, H. Clearance of apoptotic neurons without inflammation by microglial triggering receptor expressed on myeloid cells-2. J. Exp. Med. 201, 647-657 (2005).

26. Ries, M. \& Sastre, M. Mechanisms of A $\beta$ clearance and degradation by glial cells. Front. Aging Neurosci. 8, 160 (2016).

27. Lemarchant, S. et al. Anti-inflammatory effects of ADAMTS-4 in a mouse model of ischemic stroke. Glia 64, 1492-1507 (2016).

28. Steinberg, S. et al. Loss-of-function variants in ABCA7 confer risk of Alzheimer's disease. Nat. Genet. 47, 445-447 (2015).

29. Fu, Y. et al. ABCA7 mediates phagocytic clearance of amyloid- $\beta$ in the brain. J. Alzheimers Dis. 54, 569-584 (2016).

30. Kettenmann, H. et al. Physiology of microglia. Physiol. Rev. 91, 461-553 (2011).

31. Wendt, S. et al. Experimental cortical spreading depression induces NMDA receptor dependent potassium currents in microglia. J. Neurosci. 36, 6165-6174 (2016)

32. Takeda, A. et al. Microglia mediate non-cell-autonomous cell death of retinal ganglion cells. Glia 66, 2366-2384 (2018).

33. Murugan, M. et al. Expression of N-methyl D-aspartate receptor subunits in amoeboid microglia mediates production of nitric oxide via NF- $\kappa B$ signaling pathway and oligodendrocyte cell death in hypoxic postnatal rats. Glia 59, 521-539 (2011).

34. Gilling, K. E. et al. Potency, voltage-dependency, agonist concentration-dependency, blocking kinetics and partial untrapping of the uncompetitive N-methyl-D-aspartate (NMDA) channel blocker memantine at human NMDA (GluN1/GluN2A) receptors. Neuropharmacology 56, 866-875 (2009).

35. Parsons, C. G. et al. Patch clamp studies on the kinetics and selectivity of N-methyl-D-aspartate receptor antagonism by memantine (1-amino-3,5-dimethyladamantan). Neuropharmacology 32, 1337-1350 (1993).

36. Liu, W. et al. Memantine, a low-affinity NMDA receptor antagonist, protects against methylmercury-induced cytotoxicity of rat primary cultured cortical neurons, involvement of $\mathrm{Ca} 2+$ dyshomeostasis antagonism, and indirect antioxidation effects. Mol. Neurobiol. 54, 5034-5050 (2017). 
37. Mizoguchi, Y. et al. Brain-derived neurotrophic factor induces sustained elevation of intracellular Ca2+ in rodent microglia. J. Immunol. 183, 7778-7786 (2009).

38. Patel, V. H., Brack, K. E., Coote, J. H. \& Ng, G. A. A novel method of measuring nitricoxide-dependent fluorescence using 4,5-diaminofluorescein (DAF-2) in the isolated Langendorff-perfused rabbit heart. Pflugers Archiv. 456, 635-645 (2008).

39. Kato, T. et al. Inhibitory effects of aripiprazole on interferon-gammainduced microglial activation via intracellular Ca2+ regulation in vitro. J. Neurochem. 106, 815-825 (2008).

40. Fleisher-Berkovich, S. et al. Distinct modulation of microglial amyloid $\beta$ phagocytosis and migration by neuropeptides (i). J. Neuroinflammation 7, 61 (2010).

41. Ries, M. et al. The anti-inflammatory Annexin A1 induces the clearance and degradation of the amyloid- $\beta$ peptide. J. Neuroinflammation 13, 234 (2016).

42. Keren-Shaul, H. et al. Unique microglia type associated with restricting development of Alzheimer's disease. Cell 169, 1276-1290 (2017).

43. Hong, S. et al. Complement and microglia mediate early synapse loss in Alzheimer mouse models. Science 352, 712-716 (2016).

44. Streit, W. J. et al. Microglial activation occurs late during preclinical Alzheimer's disease. Glia 66, 2550-2562 (2018).

45. Shah, V. B. et al. Beta-glucan activates microglia without inducing cytokine production in Dectin-1-dependent manner. J. Immunol. 180, 2777-2785 (2008).

46. Akitake, Y. et al. Microsomal prostaglandin E synthase-1 is induced in Alzheimer's disease and its deletion mitigates Alzheimer's disease-like pathology in a mouse model. J. Neurosci. Res. 91, 909-919 (2013).

47. Qin, H. et al. Signal transducer and activator of transcription-3/suppressor of cytokine signaling-3 (STAT3/SOCS3) axis in myeloid cells regulates neuroinflammation. Proc. Natl. Acad. Sci. USA 109, 5004-5009 (2012).

48. Iwahara, N. et al. Role of suppressor of cytokine signaling 3 (SOCS3) in altering activated microglia phenotype in APPswe/PS1dE9 Mice. J. Alzheimers Dis. 55, 1235-1247 (2017).

49. Gunner, G. et al. Sensory lesioning induces microglial synapse elimination via ADAM10 and fractalkine signaling. Nat. Neurosci. 22, 1075-1088 (2019).

50. Jansen, I. E. et al. Genome-wide meta-analysis identifies new loci and functional pathways influencing Alzheimer's disease risk. Nat. Genet. 51, 404-413 (2019).

51. Qian, M., Shen, X. \& Wang, H. The distinct role of ADAM17 in APP proteolysis and microglial activation related to Alzheimer's disease. Cell. Mol. Neurobiol. 36, 471-482 (2016).

52. Sommer, D. et al. ADAM17-deficiency on microglia but not on macrophages promotes phagocytosis and functional recovery after spinal cord injury. Brain Behav. Immun. 80, 129-145 (2019).

\section{Author contributions}

T.M.-H. and Y.M. contributed to design of the study and wrote the paper. Y.H. and M.O. contributed to the acquisition and analysis of data. A.M. contributed to the acquisition and interpretation of data. Each author approved the submitted version and agreed both to be personally accountable for each own contributions and to ensure that questions related to the accuracy or integrity of any part of this work.

\section{Competing interests}

The authors declare no competing interests.

\section{Additional information}

Supplementary Information The online version contains supplementary material available at https://doi. org/10.1038/s41598-021-85625-4.

Correspondence and requests for materials should be addressed to Y.M.

Reprints and permissions information is available at www.nature.com/reprints.

Publisher's note Springer Nature remains neutral with regard to jurisdictional claims in published maps and institutional affiliations.

(c) (i) Open Access This article is licensed under a Creative Commons Attribution 4.0 International License, which permits use, sharing, adaptation, distribution and reproduction in any medium or format, as long as you give appropriate credit to the original author(s) and the source, provide a link to the Creative Commons licence, and indicate if changes were made. The images or other third party material in this article are included in the article's Creative Commons licence, unless indicated otherwise in a credit line to the material. If material is not included in the article's Creative Commons licence and your intended use is not permitted by statutory regulation or exceeds the permitted use, you will need to obtain permission directly from the copyright holder. To view a copy of this licence, visit http://creativecommons.org/licenses/by/4.0/.

(c) The Author(s) 2021 